\title{
ANALISIS TINGKAT RESIKO PEMBIAYAAN PADA KSPPS BMT AMANAH RAY CABANG SUTRISNO MEDAN
}

\author{
Siti Fadila, Rusdiono, Wahyu Sri Haryani \\ Alumni Sekolah Tinggi Ilmu Manajemen Sukma \\ Program studi Manajemen, Sekolah Tinggi Ilmu Manajemen \\ rusdiono0670@gmail.com,wahyusrihariyani@gmail.com
}

ABSTRACT

The purpose of this study is to determine the level of financing risk on KSPPS BMT Amanah Ray Branch Sutrisno Medan. Medote that writer use in this research is quantitative descriptive method, that is by collecting and analyzing data related to problem faced. The author analyzed data in the form of financing data reports on KSPPS BMT Amanah Ray Branch Sutrisno from 2014 until 2016. The results showed based on the analysis that the Non Performing Loan (NPL) Financing in KSPPS BMT Amanah Ray Branch SutrisnoMedan from 2014 until 2016 fluctuate every year. Viewed from the average percentage of risk level KSPPS BMT Amanah Ray Branch Sutrisno set by Bank Indonesia (BI) is 5\% below the percentage for low category loans with an average amount of 0,02\%. This means that Non Performing Loans (NPLs) for three consecutive years from 2014 to 2016 is low.

Keywords: Financing Risk, KSPPS BMT Amanah Ray

\section{PENDAHULUAN}

Pembiyaan salah satu bagian pembentukan modal yang dilakukan oleh koperasi simpan pinjam dan pembiayaan syariah (KSPPS) dalam hal ini pihak KSPPS ke masyarakat dalam upaya mendorong kinerja usaha sehingga dapat dimanfaatkan untuk meningkatkan produktitivitas usaha sektor rill yang dilakukan oleh masyarakat secara individu maupun kelompok. Pemberian pembiayaan merupakan kegiatan utama suatu KSPPS yang mengandung risiko yang dapat berpengaruh pada kesehatan dan kelangsungan KSPPS, sehingga dalam pengalamannya diperlukan tindakan-tindakan yang tepat, tertib dan teratur terutama bagi pembiayaan yang dikatagorikan bermasalah, pembiaayan yang bermalah itu dikarenakan tidak tepatnya waktu dalam melakukan pembayaran pembiayaan karena itu setiap KSPPS harus ekstra hati-hati dan bekerja optimal agar kesehatan dan kelangsungan kepercayaan masyarakat kepada KSPPS tersebut tetap terpelihara. Analisis pembiayaan atau penilaian pembiayaan adalah suatu proses yang dimaksud untuk menganalisa atau menilai suatu permohonan pembiayaan yang diajukan oleh calon debitur, sehingga KSPPS memiliki keyakinan bahwa anggota pembiayaan yang akan dibiayai KSPPS cukup layak. Dengan adanya analisis pembiayaan ini dapat mencegah kemungkinan terjadinya default oleh calon debitur. Default dalam hal ini merupakan kegagalan anggota dalam memenuhi kewajibannya untuk melunasi pembiayaan yang diterimanya beserta margin yang telah disepakati bersama. Untuk menghindari pembiayaan bermasalah atau Non Performing Loan (NPL), KSPPS telah melakukan analisa terhadap usaha dan pendapatan serta kemampuan debitur. 
Berdasarkan penelitian terdahulu yang dilakukan oleh Ismail (2015) dengan judul penelitian Analisis Tingkat Resiko Kredit pada PT. Bank Rakyat Indonesia, Tbk dengan hasil penelitian menunjukkan bahwa kredit Non Performing loans (NPL) pada PT. Bank Rakyat Indonesia, Tbk selama tiga tahun (2011-2013) mengalami peningkatan tiap tahunnya. Dilihat dari rata-rata prosentase tingkat risiko PT. Bank Rakyat Indonesia, Tbk yang ditetapkan oleh Bank Indonesia yaitu 5\% dibawah prosentase untuk kredit kategori rendah dengan jumlah rata-rata $1,65 \%$. Artinya Non Performing Loans (NPL) PT. Bank Rakyat Indonesia, Tbk selama tiga tahun priode (2011-2013) tergolong rendah. Penelitian terdahulu yag dilakukan oleh Lestari (2016) dengan judul penelitian Analisis Tingkat Resiko Kredit pada PT. Bank MNC Internasional, Tbk selama tiga tahun (2013-2015) mengalami penurunan tiap tahunnya. Dilihat dari rata-rata presentase tingkat resiko PT. Bank MNC Internasional, Tbk yang telah ditetapkan oleh Bank Indonesia yaitu 5\% dibawah presentase untuk kredit dikatagori rendah dengan jumlah rata-rata $0,05 \%$. Artinya Non Performing Loans (NPL) PT. MNC Internasional, Tbk selama tiga tahun priode (2013-2015) tergolong rendah.

\section{Perumusan Masalah}

Berdasarkan uraian diatas, maka perumusan masalah pada penelitian ini adalah "Bagaimana tingkat risiko pembiayaan pada KSPPS BMT Amanah Ray cabang sutrisno Medan?"

\section{Batasan Masalah}

Guna memperjelas arah penelitian ini maka penulis membatasi hanya pada data berupa laporan data pembiayaan selama tahun 2014 sampai dengan tahun 2016.

\section{Tujuan Penelitian}

Adapun tujuan penelitian ini adalah untuk mengetahui tingkat risiko pembiayaan pada KSPPS BMT Amanah Ray cabang Sutrisno Medan sejak tiga tahun terakhir 2014 sampai dengan tahun 2016.

\section{METODE PENELITIAN}

\section{Metode Pengumpulan Data}

Metode pengumpulan data dalam penelitian ini menggunakan dua metode yaitu :

1. Studi dokumentasi adalah metode pengumpulan data kualitatif dengan melihat dokumen-dokumen yang dibuat oleh subjek sendiri atau oleh orang lain tentang subjek;

2. Penelitian kepustakaan adalah penelitian ini dilakukan untuk memperoleh data skunder dengan cara menggunakan informasi dari buku-buku ataupun dari sumber lainnya;

\section{Metode Analisis Data}

Dalam penelitian ini, analisis data dilakukan secara deskriptif kuantitatif. Metode ini merupakan metode yang dilakukan dengan cara mengumpulkan dan menganalisa data yang berhubungan dengan masalah yang dihadapi. Data yang dianalisi yaitu data berupa laporan data pembiayaan pada KSPPS BMT Amanah Ray cabang Sutrisno Medan, pada tahun 2014 sampai dengan tahun 2016. 


\section{HASIL DAN PEMBAHASAN}

\section{Deskripsi Data Penelitian}

Berdasarkan data yang diperoleh dan sesuai dengan identifikasi masalah pada bab 1, hasil penelitian tentang analisis tingkat risiko pembiayan pada KSPPS BMT Amanah Ray cabang Sutrisno Medan adalah sebagai berikut:

\section{Analisis tingkat risiko kredit pada KSPPS BMT Amanah Ray Cabang Sutrisno}

Menyusun analisa tingkat risiko pembiayaan tahap-tahap yang perlu dilaksanakan dalam analisis ini adalah menganalisis dan membuat laporan data pembiayaan pada KSPPS BMT Amanah Ray Cabang Sutrisno.

Dalam kegiatan pemberian pembiayaan, khususnya KSPPS BMT Amanah Ray cabang Sutrisno Medan terdapat pengendalian pembiayaan yang bermasalah baik disengaja atau tidak. Pengendalian ini sering disebut Non Performing Loan (NPL) Atau pengembalian pembiayaan bermasalah yang terdiri dari kurang lancar, diragukan, dan macet.

Berikut ini rincian Non Performing Loans (kolektibilitas kurang lancar, diragukan, dan macet) KSPPS BMT Amanah Ray selama tiga tahun terakhir pada tabel halaman berikut :

Tabel 1 : KSPPS BMT Amanah Ray Cab. Sutrisno Medan Rincian Pembiayaan Non Performing Loan

Per 31 Desember 2014

\begin{tabular}{|c|c|}
\hline Kolektibilitas & Jumlah (Rp) \\
\hline Kurang Lancar & $92.098 .412,74$ \\
\hline Diragukan & $84.656 .116,76$ \\
\hline Macet & Rp. $\quad 87.446 .977,75$ \\
\hline $\begin{array}{l}\text { Jumlah Kredit Non Performing Loan } \\
\text { Jumlah Kredit yang diberikan }\end{array}$ & $\begin{array}{l}\text { Rp. } \quad 264.201 .507,25 \\
\text { Rp. 9.302.869.973,31 }\end{array}$ \\
\hline Kredit Non Performing Loan & 0,03 \\
\hline$\%$ Kredit Non Performing Loan & $3 \%$ \\
\hline
\end{tabular}

Sumber : KSPPS BMT Amanah Ray Cabang Sutrisno Medan (diolah)

Rincian pembiayaan Non Performing Loan per 31 Desember 2014 dilihat dari jumlah pembiayaan pada kreteria diragukan dan macet hampir sama. Sedangkan presentasi pembiayaan bermasalah dengan jumlah pembiayaan yang diberikan sebesar 3\%.

Tabel.2 : KSPPS BMT Amanah Ray Cab. Sutrisno Medan

Rincian Pembiayaan Non Performing Loan

Per 31 Desember 2015

\begin{tabular}{|c|c|}
\hline Kolektibilitas & Jumlah (Rp) \\
\hline Kurang Lancar & $56.255 .600,51$ \\
\hline Diragukan & $50.140 .861,33$ \\
\hline Macet & $48.917 .913,49$ \\
\hline $\begin{array}{l}\text { Jumlah Kredit Non Performing Loan } \\
\text { Jumlah Kredit yang diberikan }\end{array}$ & $\begin{array}{l}\text { Rp. } \quad 155.314 .375,33 \\
\text { Rp. 12.229.478.372,40 }\end{array}$ \\
\hline Kredit Non Performing Loan & 0.01 \\
\hline
\end{tabular}




\begin{tabular}{|l|c|}
\hline$\%$ Kredit Non Performing Loan & $1 \%$ \\
\hline
\end{tabular}

Sumber : KSPPS BMT Amanah Ray Cabang Sutrisno (diolah)

Rincian kredit Non Performing Loan per 31 Desember 2015 dilihat dari jumlah pembiayaan pada kriteria kurang lancar, diragukan dan macet menurun dibandingkan pada tahun 2014. Sedangkan presentase pembiayaan bermasalah dengan jumlah pembiayaan yang diberikan sebesar $1 \%$.

Tabel .3 : KSPPS BMT Amanah Ray Cab. Sutrisno Medan

Rincian pembiayaan Non Performing Loan

Per 31 Desember 2016

\begin{tabular}{|l|lc|}
\hline \multicolumn{1}{|c|}{ Kolektibilitas } & \multicolumn{2}{c|}{ Jumlah (Rp) } \\
\hline Kurang Lancar & Rp. & $62.519 .663,36$ \\
\hline Diragukan & Rp. & $51.405 .056,54$ \\
\hline Macet & Rp. & $73.634 .270,18$ \\
\hline Jumlah Kredit Non Performing Loan & Rp. $\mathbf{1 8 7 . 5 5 8 . 9 9 0 , 0 8}$ \\
Jumlah Kredit yang diberikan & Rp. 13.893.258.524.00 \\
\hline Kredit Non Performing Loan & & $0.01 \%$ \\
\hline \% Kredit Non Performing Loan & & $1 \%$ \\
\hline
\end{tabular}

Sumber : KSPPS BMT Amanah Ray Cabang Sutrisno (diolah)

Komposisi pembiayaan Non Performing Loan per 31 Desember 2016 Pada Kolektibilitas kurang lancar, diragukan dan macet mengalami peningkatan dibandingkan tahun 2015. Tetapi persentase pembiayaan bermasalah dengan jumlah pembiayaan yang diberikan sama dengan tahun 2015 yakni $0.01 \%$.

\section{Pembahasan}

Berdasarkan perhitungan tersebut, maka Non Performing Loan (NPL) tahun 20142016 dapat dirata-ratakan menjadi :

$3 \%+1 \%+1 \%=5 \%$

$\begin{aligned} \text { Jadi rata-rata NPL } & =\frac{5 \%}{3} \\ & =1,67 \%\end{aligned}$

Perhitungan tingkat risiko pembiayaan dengan menggunakan analisis Credit Risk Ratio, berdasarkan kolektibilitas pembiayaan dari KSPPS BMT Amanah Ray cabang Sutrisno Medan maka akan diperoleh sebagai berikut :

$$
\text { Bad Debts }
$$

\section{Credit Risk Ratio}

$$
\text { Total Loans }
$$

A. Credit Risk Ratio pada tahun 2014

1. Bad Debts
a. Kurang Lancar
$=$ Rp. $\quad 92.098 .412,78$
b. Diragukan
$=$ Rp. $\quad 84.656 .116,76$
c. Macet
$=$ Rp. $\quad 87.446 .977,75$
Total Loans
$=\mathbf{R p} \quad$. 264.201.507,25
Credit Risk Ratio $2014=$
Rp. $264.201 .507,25$

$$
\begin{aligned}
& \text { Rp. } 9.302 \cdot 869 \cdot 973,31 \\
& =0,03
\end{aligned}
$$




$$
=0,03 \times 100 \%=3 \%
$$

Diketahui tingkat risiko pada tahun 2014 yang ada sebesar Rp. 264.201.507,25 atau sebesar 3\% ini menunjukkan bahwa risiko pembiayaan tersebut berada dibawah resiko pembiayaan yang ditetapkan Bank Indonesia (BI) dengan presentase kelebihan sebagai berikut:

$5 \%-3 \%=2 \%$

B. Credit Risk ratio pada tahun 2015

2. Bad Debts
a. Kurang Lancar
$=$ Rp. $\quad 56.255 .600,51$
b. Diragukan
$=$ Rp. $\quad 50.140 .861,33$
c. Macet
$=$ Rp. $\quad 48.917 .913,49$
d. Total Loans
$=$ Rp. $\quad 155.314 .375,33$

$$
\begin{gathered}
\text { Credit Risk Ratio 2015 }=\quad \frac{\text { Rp. } 155.314 .375,33}{\text { Rp. } 12.229 .478 .372,40} \\
=0,01 \\
=0,01 \times 100 \%=1 \%
\end{gathered}
$$

Diketahui tingkat risiko pada tahun 2015 yang ada sebesar Rp. 155.314.375,33 atau sebesar 1\% ini menunjukkan bahwa resiko keredit tersebut berada dibawah resiko kredit yang ditetapkan Bank Indonesia (BI) dengan presentase kebelihan sebagai berikut:

$5 \%-1 \%=4 \%$

C. Credir Risk Ratio pada tahun 2016

3. Bad Debts
a. Kurang Lancar
$=\mathrm{Rp} .62 .519 .663,36$
b. Diragukan
$=$ Rp. 51.405.056,54
c. Macet
$=$ Rp. 73.634.270,18
d. Total Loans
$=$ Rp. $187.558 .930,08$
Rp.187.558.930,08

Credit Risk Ratio $2014=$

$$
\begin{aligned}
& \text { Rp. 13.893.258.524,00 } \\
& =\quad 0,01 \text { X } 0,0100 \%=1 \%
\end{aligned}
$$

Diketahui tingkat risiko pada tahun 2016 yang ada sebesar Rp. 187.558.930,08 atau sebesar 1\% ini menunjukkan bahwa resiko keredit tersebut berada dibawah resiko kredit yang ditetapkan Bank Indonesia (BI) dengan presentase kebelihan sebagai berikut:

$5 \%-1 \%=4 \%$

Tabel 4. : Nilai rata-rata presentase

Pada tahun 2014-2016

\begin{tabular}{|r|rr|rr|c|}
\hline \multirow{2}{*}{ Tahun } & \multicolumn{2}{|l|}{ Non Performing Loan( NPL) } & \multicolumn{2}{|l|}{ Pembiayaan yang diberikan } & \multicolumn{1}{l|}{$\%$} \\
\hline 2014 & $\mathrm{Rp}$ & $264,201,507.25$ & $\mathrm{Rp}$ & $9,302,869,973$ & 3 \\
\hline 2015 & $\mathrm{Rp}$ & $155,314,375.33$ & $\mathrm{Rp}$ & $12,229,478,372$ & 1 \\
\hline 2016 & $\mathrm{Rp}$ & $187,558,930.08$ & $\mathrm{Rp}$ & $13,893,258,524$ & 1 \\
\hline
\end{tabular}

Rata- rata $=1,67 \%$ 
Dapat disimpulkan bahwa dilihat dari aspek Non Performing Loan (NPL) yang terdiri dari kolektibilitas kurang kancar, diragukan dan macet. Dan persentase dari tahun ketahun mengalami fluktuatif dan nilai rata-rata persentasenya sebesar $1.67 \%$ dilihat dari tingkat kesehatan bank sebesan bank sebesar 5\% menurut ketetapan Bank Indonesia (BI), maka tingkat risiko KSPPS BMT Amanah Ray cabang Sutrisno Medan berada pada tingkat rendah. Dari data diatas jumlah kredit bermasalah dari ketahun semakin berkurang sedangkan total kredit yang diberikan semakin bertambah. Maka hal ini akan berpengaruh pada jumlah Non Performing Loan (NPL).

\section{Kesimpulan}

1. Setelah melakukan penelitian dan pembahasan bahwa analisis tingkat risiko pembiayaan pada KSPPS BMT Amanah Ray cabang Sutrisno Medan berjalan sudah cukup baik dan pembiayaan Non Performing Loans (NPL) pada KSPPS BMT Amanah Ray cabang Sutrisno Medan dari tahun 2014 sampai dengan tahun 2016 mengalami fluktuasi. Peningkatan pembiayaan bermasalah yang paling tinggi terjadi pada tahun 2014. Hal ini disebabkan oleh keadaan ekonomi yang tidak stabil yang akhirnya menyebabkan pendapatan masyarakat dan perusahaan berkurang sehingga anggota menunggak dan juga akibat dari karakter anggota yang jelek sampai akhirnya tidak dapat membayar hutang pembiayaan pada koperasi sampai waktu yang telah ditentukan.

2. Besarnya rata-rata presentase tingkat risiko pada KSPPS BMT Amanah Ray Cabang Sutrisno Medan yang ditetapkan oleh Bank Indonesia (BI) yaitu presentase untuk pembiayaan kategori rendah dengan jumlah rata-rata 0,03\%. Artinya Non Performing Loans (NPL) KSPPS BMT Amanah Ray cabang Sutrisno Medan selama tiga tahun priode dari tahun 2014 sampai dengan tahun 2016 tergolong rendah. 


\section{REFERENCES}

Batubara, A., \& Hidayat, R. (2016). Pengaruh Penetapan Harga dan Promosi terhadap Tingkat Penjualan Tiket pada PSA Mihin Lanka Airlines. Jurnal Ilman, 4(1), 33-46.

Cece. (2003). Analisis Hubungan Perencanaan Strategi Aliansi PDAM Tirtanadi-PT. Telekominikasi Divre I Terhadap Peningkatan Kualitas Pelayanan Pelanggan PDAM Tirtanadi... Universitas Sumatera Utara.

Dinamika, S. G. (2018). Gemstone Fever Hits Jakarta: A Lexical Meaning Analysis.

Dinamika, S. G., \& Sari, W. V. (2015). Applied Error Analysis of Comparative Degree Sentence Construction of Students in STIM Sukma Medan. Asian EFL Journal, 5, 112-119.

Dinamika, Soraya Grabiella (2014) THE EFFECT OF USING COLLABORATIVE STRATEGIC READING ON STUDENTS' ACHIEVEMENT IN READING NARRATIVE TEXT. Undergraduate thesis, UNIMED

Fahmi, I. (2014). Manajemen Perkreditan. (M. A. Djalil, Ed.). Bandung: Alfabeta.

Fathimah, V. (2017). Pengaruh Perkembangan Jumlah Tabungan, Deposito dan Bagi Hasil terhadap Jumlah Pembiayaan yang Diberikan oleh Perbankan Syariah di Sumatera Utara. Jurnal Ilman, $5(1), 41-52$.

Ismail. (2015). Analisi Tingkat Risiko Kredit Pada Bank Rakyat Indonesia, Tbk. Stim Sukma Medan.

Karim, F. R. (2017). Analisis Penilaian Tingkat Kesehatan Koperasi Simpan Pinjam dan Pembiayaan Syariah (KSPPS). Universitas Islam Negeri Syarif Hidayahtullah.

Lestari, D. N. (2016). Analisi Tingkat Risiko Kredit Pada Bank MNC Internasional, Tbk. Stim Sukma Medan.

Lubis, D. I. D., \& Hidayat, R. (2017). Pengaruh Citra Merek dan Harga terhadap Keputusan Pembelian pada Sekolah Tinggi Ilmu Manajemen Sukma Medan. Jurnal Ilman, 5(1), 15-24.

Muhammad. (2016). Sistem Bagi Hasil dan Pricing Bank Syariah. UII Press.

Nasution, W. A. (2009). Pengaruh kepuasan kerja karyawan terhadap intensi turnover pada call center Telkomsel di Medan. Jurnal Mandiri, 4(1), 1-11.

Nasution, W. A. (2013). Pengaruh kompensasi dan lingkungan kerja terhadap kepuasan kerja karyawan pada PT. Karya Deli Stelindo Medan. Jurnal Manajemen Bisnis STIE IBBI, 20(2), 177.

Nasutiona, L. K., Fahrurb, M., Christine, Imaduddind, \& Wardayani. (2017). The Calculation of Cost of Goods Sold "Gayo Arabica Coffee from Takengon" with Variable Costing Method. Journal Online Jaringan COT POLIPD (JOJAPS), 10, 82-87.

Ningratri, Y. A. (2017). Analisis Pengaruh Strategi Bauran Pemasaran Jasa (3P) terhadap Keputusan Mahasiswa Memilih STIM Sukma Medan. Riset \& Ejurnal Manajemen Informatika, 3(1), 5056.

Nurlinda, \& Wardayani. (2014). Pengaruh Partisipasi Penyusunan Anggaran Dan Penggunaan Instrumen Manajemen Terhadap Kinerja Pengelolaan Dana Bantuan Global Fund Komponen Aids Pada Kementerian Kesehatan Ri. Jurnal Ilman, 1(1), 23-35.

Prana, R. R. (2016). Analisis Faktor-faktor yang Mempengaruhi Pendapatan Asli Daerah (PAD) Kota Tebing Tinggi. Jurnal Ilman, 4(1), 74-86.

Raidani, Pertiwi, L. S., Wulandari, D. Y., \& Zuhri. (2016). Tobit and Interval Censored Regression Model. Global Journal of Pure and Applied Mathematics, 12(1), 981-994. 
Sabdillah, R., Hidayat, R., Lubis, D. S. W., \& Wardayani. (2017). Influence of Celebrity Endorser Raisa Andriana in Advertisement on Magnum Ice Cream Brand Image on the Transmart Costumers. Journal Online Jaringan Pengajian Seni Bina (JOJAPS), 10, 112-115.

Safriandi, F., Pertiwi, L. S., Fitriani, A., \& Zuhri. (2016). Truncated Regression Model and Nonparametric Estimation for Gifted and Talented Education Program. Global Journal of Pure and Applied Mathematics, 12(1), 995-1002.

Sinaga, S., Pertiwi, L. S., Ardian, T., \& Zuhri. (2016). Inventory Simulation Optimization Under Non Stationary Demand. International Journal of Applied Engineering Research, 11(1), 524-529.

Sinuhaji, E. (2010). PENERAPAN LAYANAN UNGGUL DALAM PEMASARAN PRODUK BANK. Jurnal Mediasi, 2(1).

Sinuhaji, E. (2013). PENGARUH BUDAYA ORGANISASI TERHADAP KEPUASAN KERJA KARYAWAN PADA JASA PERHOTELAN (Studi Kasus di Garuda Plaza Hotel Medan). Bisnis Administrasi, 2(1), 2537.

Sinuhaji, E. (2014). Pengaruh Kepribadian, Kemampuan Kerja dan Motivasi Kerja terhadap Kinerja SDM Outsourcing pada PT. Catur Karya Sentosa Medan. Jurnal Ilman, 1(1), 11-22.

Soemitra. (2016). Bank dan Lembaga Keuangan Syariah (Ke-Dua). Jakarta: KENCANA.

Sukendro, H. A. (2012). Pengaruh Citra Merek dan Kualitas Pelayanan terhadap Kepuasan Jama'ah pada Kelompok Bimbingan Ibadah Haji (KBIH) Indosat Medan. Universitas Terbuka.

Sunyoto, D. (2016). Metodologi Penelitian Akuntansi. (A. Gunarsa, Ed.) (2nd ed.). PT. Refika Aditama.

Surat Edaran Bank Indonesia No. 15/35/DPAU. Penentuan NPL. (2013). Retrieved from www.bi.co.id

Surat Edaran Bank Indonesia No.13/30/DPNP. Rumus NPL. (2013). Retrieved from $\underline{\text { www.bi.co.id }}$

Sutrisno. (2013). Analisis Sistem Pemberian Pembiaayan Murabahah Pada PT.BPR Syariah Adeco Langsa. Stim Sukma Medan.

Tanjung, I. F. (2015). Penanganan Pembiayaan Bermasalah Di BMT Amanah Mulia Magelang.

Unsur Tujuan Pembiayaan. (2014). Retrieved from http://www.kajianpustaka.com/2014/02/

Wahyuni, D. S., \& Wardayani. (2016). Analisis Return on Asset, Current Ratio dan Debt Ratio dalam Menilai Kinerja Keuangan pada PT . Pelabuhan Indonesia I (Persero) cabang Belawan. Jurnal Ilman, 4(1), 59-73.

Widjanarko, B. (2015). PENGARUH PEMERIAN KOMPENSASI DAN KOMUNIKASI TERHADAP SEMANGAT KERJA KARYAWAN PADA BUMI KARYA TAMA INSURANCE CABANG MEDAN. Jurnal Research Sains, 1(2), 130-152.

Winata, E. (2016). Pengaruh Kepuasan Kerja dan Kompensasi terhadap Kinerja Karyawan pada Hotel Inna Dharma Deli Medan. Jurnal Ilman, 4(1), 1-17.

Winata, E. (2016). PENGARUH KOMPENSASI DAN KOMUNIKASI TERHADAP SEMANGAT KERJA KARYAWAN PADA PT. FIF CABANG MEDAN. Jurnal Dunia Ilmu, 2(1), 17-31.

Winata, E. (2017). PENGARUH BAURAN PEMASARAN JASA TERHADAP LOYALITAS KONSUMEN PADA GRAND SERELA HOTEL \& CONVENTION MEDAN. Jurnal Mutiara Manajemen, 1(1), 109-121. 